\title{
Consequences of the ion beam irradiation on the chemical durability of Thorium Phosphate Diphosphate - Kinetics study.
}

C. Tamain ${ }^{1}$, N. Dacheux* ${ }^{1}$, F. Garrido ${ }^{2}$, A. Habert ${ }^{1}$, N. Barré ${ }^{1}$, A. Özgümüs ${ }^{1}$, L. Thomé ${ }^{2}$

${ }^{1}$ Groupe de Radiochimie, Institut de Physique Nucléaire, Bât.100, Université Paris-Sud-11, 91406 Orsay, France.

${ }^{2}$ Centre de Spectrométrie Nucléaire et de Spectrométrie de Masse, CNRS-IN2P3-Université Paris-Sud-11, Bât.108, 91405 Orsay, France.

* Corresponding author: DACHEUX Nicolas

Groupe de Radiochimie

Institut de Physique Nucléaire

Université de Paris-Sud-11, Bât. 100

91406 Orsay, France.

Phone: $\quad+33169157346$

Fax: $\quad+33169157150$

E-mail: dacheux@ipno.in2p3.fr 


\section{Abstract}

In the field of the long-term specific immobilization of actinides, Thorium Phosphate Diphosphate ( $\beta$-TPD), as potential candidate, must respond to several criteria. Among them, the material must present a good resistance to irradiation and keep its initial good properties such as resistance to aqueous alteration. In order to check this later point, sintered samples of $\beta$-TUPD solid solutions were pre-irradiated with ion beams with various conditions (fluence, stopping power) then submitted to leaching tests in different media ( $\mathrm{pH}$, temperature, complexing reagents, flow rate, ...). The normalized dissolution rates depend significantly on the amorphous fraction (increase by a factor of 10-100 between unirradiated and fully amorphized materials). On the contrary, the pre-irradiation of the samples does not affect the kinetic parameters of the dissolution such as the partial order relative to the proton concentration $(n=0.37 \pm 0.01$ and $n=0.34 \pm 0.01$ for unirradiated and fully amorphized samples, respectively) and the activation energy of the reaction of dissolution $\left(E_{\text {app }}=49 \pm 4\right.$ $\mathrm{kJ} \mathrm{mol}^{-1}$ and $E_{\text {app }}=42 \pm 4 \mathrm{~kJ} \mathrm{~mol}^{-1}$ for unirradiated and partly amorphized samples $\left(f_{\mathrm{A}}<1\right)$, respectively). 


\section{Introduction}

The French law relative to the management of radwaste coming from the back-end of the nuclear fuel cycle defines their storage in an underground repository as a likely option [1]. In this aim, many research activities were carried out to propose phosphate-based ceramic materials for the final disposal of minor actinides such as $\mathrm{Am}, \mathrm{Cm}$ or $\mathrm{Np}$. On the basis of the results obtained in the field of actinides weight loadings, sintering capability, chemical durability and resistance to radiation damage, four ceramics (one titanate-based material and three phosphate-based materials) were selected as potential actinide-bearing host-matrices: zirconolite $\left(\mathrm{CaZrTi}_{2} \mathrm{O}_{7}\right)$ [2-4], britholites $\left(\mathrm{Ca}_{9} \mathrm{Nd}\left(\mathrm{PO}_{4}\right)_{5}\left(\mathrm{SiO}_{4}\right) \mathrm{F}_{2}\right)$ [5-6], monazites $\left(\mathrm{LnPO}_{4}\right)$ and associated brabantites $\left(\mathrm{N}^{\mathrm{II}} \mathrm{M}^{\mathrm{IV}} \mathrm{PO}_{4}\right)$ [7-13], and thorium-actinide phosphate-diphosphate solid solutions $\left(\beta-\mathrm{Th}_{4-x} \mathrm{An}_{x}\left(\mathrm{PO}_{4}\right)_{4} \mathrm{P}_{2} \mathrm{O}_{7}\right)$ with associated $\beta$-TPD / monazite materials [14-19].

Previous studies showed that this material presents a high resistance to aqueous alteration and exhibits a good thermal stability [20]. Since Thorium Phosphate Diphosphate $(\beta$-TPD) appears as an efficient actinide-bearing phase for the immobilization of large amounts of tetravalent actinides (up to $47.6 \mathrm{wt} . \%$ in uranium) [16-17] and small quantities of trivalent ones $(<0.5 \mathrm{wt} . \%)$ [21], its resistance to irradiation must be considered. Indeed, due to the actinide loading, self-irradiation by alpha-decays could modify the performances previously demonstrated: the emitted $\alpha$-particles $(\sim 5-\mathrm{MeV})$ essentially disperse their energy through ionization and electronic excitations, while recoil nuclei $(\sim 100 \mathrm{keV})$ lose their energy mainly through ballistic processes involving elastic collisions and causing direct atomic displacements [22-23]. These phenomena induce the formation of cascades of defects (vacancies and interstitial atoms) and can lead to the complete amorphization of the material. Such radiation damage can affect the chemical properties of the ceramic such as its chemical durability [24]. 
$\beta$-TPD and associated $\beta$-TUPD solid solutions can be prepared through the initial precipitation of crystallized low-temperature precursors identified to the Thorium Phosphate HydrogenPhosphate Hydrate $\left(\mathrm{Th}_{2}\left(\mathrm{PO}_{4}\right)_{2}\left(\mathrm{HPO}_{4}\right) \cdot \mathrm{H}_{2} \mathrm{O}, \mathrm{TPHPH}\right)$ and associated TUPHPH solid solutions [25-27]. These solids allow the further preparation of dense pellets following a twostep procedure composed by an uniaxial pressing at room temperature $(100-800 \mathrm{MPa})$ and a heat treatment at high temperature $\left(T=1250^{\circ} \mathrm{C}\right)[28,29]$. Leaching tests performed in various acidic media revealed a good chemical durability of the unirradiated pellets with normalized dissolution rates ranging from $(5.8 \pm 0.3) \times 10^{-6} \mathrm{~g} \mathrm{~m}^{-2}$ day $^{-1}$ (in $\left.10^{-1} \mathrm{M} \mathrm{HNO}_{3}\right)$ to $(4.8 \pm 0.3) \times$ $10^{-8} \mathrm{~g} \mathrm{~m}^{-2}$ day $^{-1}$ (at $\mathrm{pH}=7$ ) at room temperature which appears to be several orders for magnitude lower than that of other matrices such as basaltic glasses [30].

The structural consequences of irradiation of $\beta$-TPD were already reported in our published works [31,32]. $\beta$-TPD and associated $\beta$-TUPD solid solutions were irradiated with ion beams. The resulting amorphization was complete, partial or unexistent depending on the stopping power of the bombarding ion. This previous work also showed that $\beta$-TPD and $\beta$ TUPD present the same behavior under irradiation.

The study reported in this paper deals with the consequences of the structural alteration consecutive to external pre-irradiation on the chemical durability of $\beta$-TPD. The leaching tests were preferentially realized on $\beta-\mathrm{Th}_{3.6} \mathrm{U}_{0.4}\left(\mathrm{PO}_{4}\right)_{4} \mathrm{P}_{2} \mathrm{O}_{7}$ samples. Indeed, the substitution of thorium by uranium (IV) does not modify the structural properties of the ceramic and makes possible the determination of the dissolution kinetics by using uranium ions as a tracer of alteration. Indeed, contrarily to thorium which quickly precipitates with phosphate anions as neoformed phosphate-based phases, uranium (IV) is oxidized into uranium (VI) which remains in solution [33]. As $\beta$-TPD and $\beta$-TUPD samples present the same behavior under irradiation, it was thus possible to simulate the behavior of $\beta$-TPD towards the alteration of $\beta$-TUPD solid solutions. 


\section{Experimental}

\subsection{Preparation of $\beta$-TUPD solid solutions}

Chemical reagents including thorium nitrate pentahydrate were supplied by VWR, Merck and Aldrich-Fluka. Concentrated thorium chloride solutions $(\mathrm{C} \approx 1.8 \mathrm{M})$ were issued from Rhône-Poulenc (France) while uranium chloride solution resulted from the dissolution of uranium metal chips in $4 \mathrm{M}$ hydrochloric acid. The initial solutions were diluted in order to obtain a final concentration of $0.7 \mathrm{M}$ for thorium and $1.1 \mathrm{M}$ for uranium (IV).

As already described in previously published works, TUPHPH (of formula $\left.\mathrm{Th}_{2-\mathrm{x} / 2} \mathrm{U}_{\mathrm{x} / 2}\left(\mathrm{PO}_{4}\right)_{2}\left(\mathrm{HPO}_{4}\right) \cdot \mathrm{H}_{2} \mathrm{O}\right)$ was synthesized through a wet chemical route involving a precipitation step [25] from a mixture of thorium nitrate or chloride solution $(0.7 \mathrm{M})$ and $5 \mathrm{M}$ phosphoric acid in the mole ratio $\mathrm{Th} / \mathrm{PO}_{4}=2 / 3$. This mixture was put in a $23 \mathrm{~mL}$ PTFE closed container. The gel initially formed was slowly transformed into the well crystallized TUPHPH by heating at $150-160^{\circ} \mathrm{C}$ on a sand bath for several hours. The precipitates were separated from the supernatant by filtration or centrifugation at $4000 \mathrm{rpm}$, washed several times with deionized water then ethanol and finally dried at $100^{\circ} \mathrm{C}$ for few hours.

$\beta$-TUPD sintered pellets were obtained after pressing uniaxially the resulting powder at room temperature $(200 \mathrm{MPa})$ then heating at $1250^{\circ} \mathrm{C}$ for 10 hours in alumina boats under an inert atmosphere (argon) in Pyrox HM 40 or Adamel FR 20 furnaces.

Samples were characterized by Electron Probe MicroAnalyses (EPMA) using a Cameca SX 50 apparatus with an acceleration voltage of $15 \mathrm{kV}$ and a current of $10 \mathrm{nA}$. The calibration standards were $\mathrm{SmPO}_{4}\left(\mathrm{~K}_{\alpha}\right.$ ray of phosphorous), $\mathrm{ThO}_{2}\left(\mathrm{M}_{\alpha}\right.$ ray of thorium) and $\mathrm{UO}_{2}\left(\mathrm{M}_{\beta}\right.$ ray of uranium). The counting time was fixed to $10-30$ seconds for a spot size of $1 \mu \mathrm{m}$. The 
analyses enabled to check the homogeneity, the purity and the elementary composition of the sintered samples before irradiation.

\subsection{Ion beam irradiations}

The structural stability of the matrix under irradiation was first studied using high energy heavy-ions which interact with the material mainly by excitation and ionization (electronic energy loss) except at the end of the path of ions where the nuclear contribution predominates. Such experiments enabled to study the influence of the electronic energy loss. The irradiation experiments were performed on the SME line at GANIL (Caen, France) using 840-MeV Kr and 410-MeV S ion beams.

Other irradiations with heavy ions (4-MeV Au) at intermediate energy were performed on the ARAMIS facility at CSNSM (Orsay, France) to study the influence of the nuclear stopping power.

Each irradiated sample was characterized through XRD experiments. The diagrams were collected with a Brücker D8 Advanced Roentgen diffractometer system using $\mathrm{Cu} \mathrm{K}_{\alpha}$ rays $\left(\lambda=1.5418 \AA\right.$ ). The amorphous fraction $f_{\mathrm{A}}$ of irradiated samples, which gives the relative ratios of the amorphous and crystalline phases, was evaluated from the net areas of the XRD lines by using the following formula:

$$
f_{A}=1-\frac{\sum_{i=1}^{x} \frac{A_{i}^{\text {irradiated }}}{A_{i}^{\text {nirradiated }}}}{x}
$$

where $A_{i}^{\text {irradiated }}$ and $A_{i}^{\text {unirradiated }}$ represent the net area of the $i^{\text {th }}$ XRD line in the diagram of the irradiated and unirradiated sample, respectively.

The X-rays maximum penetration in $\beta$-TUPD samples was about $10 \mu \mathrm{m}$. The projected range $R_{\mathrm{P}}$ and the range straggling $\Delta R_{\mathrm{P}}$ were estimated with the SRIM code [34] to $R_{\mathrm{P}}=72 \mu \mathrm{m}$ 
and $\Delta R_{\mathrm{P}}=0.79 \mu \mathrm{m}$ for with $840-\mathrm{MeV} \mathrm{Kr}$, and to $R_{\mathrm{P}}=0.70 \mu \mathrm{m}$ and $\Delta R_{\mathrm{P}}=0.17 \mu \mathrm{m}$ for $4-\mathrm{MeV}$ $\mathrm{Au}$, respectively. Consequently, XRD diagrams were collected using the grazing mode for Au-irradiated samples in order to probe only the irradiated thickness.

\subsection{Leaching experiments}

Since the normalized dissolution rates of $\beta$-TUPD are very low, the leaching experiments were carried out in acidic media in order to accelerate the dissolution process and to make the influence of irradiation on the chemical durability observable on the time scales of the laboratory. Two kinds of leaching experiments were performed in this study.

The "static" batch experiments correspond to a low renewal of the leachate. They were performed in High Density PolyEthylene containers for experiments performed at room temperature and in PTFE vessels for those carried out above $343 \mathrm{~K}$. For each dissolution test, $30-200 \mathrm{mg}$ of sintered $\beta$-TUPD was put in contact with $10 \mathrm{~mL}$ of leaching solution for few days to several years. Small aliquots $(200-500 \mu \mathrm{L})$ were removed then analyzed at regular time intervals.

Due to the low renewal of the leachate, saturation conditions were easily reached, leading to the formation of neoformed phosphate-based phases. In order to limit these saturation phenomena which could alter the accurate determination of the normalized dissolution rates, some experiments were performed in dynamic conditions in $30 \mathrm{~mL}$ - PTFE flow-rate reactors as described in the literature [35]. The leaching solution (deionized water or acidic media) was injected into the flow-reactors through a $10 \mu \mathrm{m}$ filter by means of a peristaltic pump. The renewal of the leachate was evaluated to $25 \mathrm{~mL}^{-1 a y}{ }^{-1}$ (which corresponds to a daily renewal of the global volume). 
The concentrations of cations were then determined in the leachate by Inductively Coupled Plasma - Mass Spectroscopy (ICP-MS) for Th and U and by Time-Resolved Laser Induced Fluorescence Spectroscopy (TRLIFS) for U [33].

\section{Theoretical section of dissolution}

\subsection{Expression of the normalized leaching and of the normalized dissolution rate}

As already described [36], the leachability of the element $i$ from the solid is usually expressed through its normalized leaching, $N_{\mathrm{L}}(\mathrm{i})$, defined by the relation:

$$
N_{L}(i)=\frac{m_{i}}{x_{i} \times S}
$$

where $m_{i}$ is the total amount of $i$ released in solution $(\mathrm{g}), S$ corresponds to the solid area $\left(\mathrm{m}^{2}\right)$ in contact with the solution and $x_{i}$ is the mass ratio of the element $i$ in the solid. $N_{\mathrm{L}}(\mathrm{i})$ represents the normalized leaching of the element $i$ and is expressed in $\mathrm{g} \mathrm{m}^{-2}$.

The normalized dissolution rate $R_{L}\left(\mathrm{~g} \mathrm{~m}^{-2}\right.$ day $\left.^{-1}\right)$ is deduced from the evolution of this normalized leaching $N_{\mathrm{L}}(i)$ by using the following equation:

$$
R_{L}(i)=\frac{d N_{L}(i)}{d t}=\frac{d}{d t}\left(\frac{C_{i} \times V \times M_{i}}{x_{i} \times S}\right)=\frac{V \times M_{i}}{x_{i} \times S} \times \frac{d C_{i}}{d t}
$$

where $C_{i}$ represents the concentration of the elements (Th, $\left.\mathrm{U}\right)$ measured in the leachate, $V$ the volume of the leachate, $x_{i}$ the mass ratio of the element $i$ in the solid, $M_{i}$ the molar mass of the element $i$ and $S$, the surface area of the pellet $\left(\mathrm{m}^{2}\right)$.

Specific areas of the sample $\left(\mathrm{m}^{2} \mathrm{~g}^{-1}\right)$ were measured by BET before and after irradiation. It appeared that there was no significant influence of the amorphous fraction on the specific area. Thus we have considered a unique average surface area for the whole sample (irradiated and unirradiated faces) during the leaching rate calculations. 


\subsection{Description of the dissolution}

As already described, the dissolution of a ceramic can be summarized by three steps [37]. Far from equilibrium conditions, the normalized dissolution rates are usually constant and characteristic of the given minerals or materials [38-40]. On the contrary, near the thermodynamic equilibria, a parabolic evolution of $N_{\mathrm{L}}(\mathrm{i})$ can be observed due to diffusion phenomena occurring through neoformed phases or passivation layers formed onto the surface of the leached samples. Consequently, in order to evidence the influence of the amorphous fraction on the normalized dissolution rate of $\beta$-TUPD, the $R_{\mathrm{L}}$ values were determined at the beginning of the leaching tests, where the dissolution is only driven by kinetic processes in the absence of saturation phenomena.

The study of the dissolution of the materials can be described by the release of the constitutive elements from the solid to the leachate. If the normalized dissolution rates determined for each element are identical, the dissolution can be qualified to be "congruent" [36]. On the contrary, the dissolution is called "incongruent" when one element is significantly retained inside of the phases of degradation formed onto the surface of the samples or from the elements present in the leachate. In the case of $\beta$-TUPD, thorium and uranium releases were examined since both actinides exhibit different redox properties. Indeed, consequently to its oxidation into uranyl, uranium is more easily released while tetravalent thorium usually precipitates quickly.

\subsection{Dependence of the normalized dissolution rate on $\mathrm{pH}$ or on temperature.}


Several authors, who investigated the kinetics of dissolution reactions occuring between minerals and aqueous solutions [33,41-46], showed that the proton concentration has a strong effect on the normalized dissolution rate determined in acidic media:

$$
R_{\mathrm{L}}=k^{\prime}{ }_{T}\left(a_{\mathrm{H}_{3} \mathrm{O}^{+}}\right)^{\mathrm{n}}=k^{\prime}{ }_{T}\left(\gamma_{\mathrm{H}_{3} \mathrm{O}^{+}}\left[\mathrm{H}_{3} \mathrm{O}^{+}\right]\right)^{\mathrm{n}}=k_{T, I}^{\prime}\left[\mathrm{H}_{3} \mathrm{O}^{+}\right]^{\mathrm{n}}
$$

where $k_{T}^{\prime}$ and $k_{T, I}^{\prime}$ correspond to the apparent normalized dissolution rate constants $\left(\mathrm{g} \mathrm{m}^{-2} \mathrm{day}^{-1}\right), a_{\mathrm{H}_{3} \mathrm{O}^{+}}$refers to the proton activity, $\gamma_{\mathrm{H}_{3} \mathrm{O}^{+}}$corresponds to the proton activity coefficient and $n$ is the partial order with respect to the proton concentration. For most of the materials and minerals, the partial order $n$ values are usually in the range $0<n<1[33,41]$. For unirradiated $\beta$-TUPD, it reaches 0.39 - 0.41 [36].

Moreover, the influence of the temperature on the normalized dissolution rate can be described by the following Arrhenius law [47]:

$$
R_{L}=k \times e^{\frac{-E_{a p p}}{R T}}
$$

where $k$ is the normalized dissolution rate constant $\left(\mathrm{g} \mathrm{m}^{-2}\right.$ day $\left.^{-1}\right)$ independent of the temperature (but $\mathrm{pH}$-dependent) and $E_{\text {app }}$ corresponds to the apparent activation energy of the dissolution $\left(\mathrm{kJ} \mathrm{mol}^{-1}\right)$.

The partial order of proton and the activation energy were determined to evaluate the effects of $\mathrm{pH}$ and temperature on the dissolution of pre-irradiated $\beta$-TUPD samples.

\section{Results and discussion}


Only one face of the cylindrical leached samples was irradiated on a $72 \mu \mathrm{m}$-thickness; the rest of the surface corresponds to unirradiated material. The amorphous fraction $f_{\mathrm{A}}$ characterized the first 10 micrometers probed by XRD nearby the surface on the irradiated face.

The first aim of this study dealt with the influence of a pre-irradiation on the kinetics of $\beta$-TUPD dissolution. In this context, several samples were first irradiated with $840-\mathrm{MeV}$ $\mathrm{Kr}$ ion beam at different fluences, which led to various amorphous fractions $f_{\mathrm{A}}$. For both actinides (Th, U), the evolution of the normalized leachings $N_{\mathrm{L}}(\mathrm{U})$ and $N_{\mathrm{L}}(\mathrm{Th})$ were followed in $10^{-1} \mathrm{M} \mathrm{HNO}_{3}$ at $363 \mathrm{~K}$ using "static" conditions (Fig. 1). Data reported in previous published works for unirradiated $\beta$-TUPD samples [36] were used as references.

For all samples considered, the data obtained revealed that the dissolution of preirradiated $\beta$-TUPD is congruent in the first days in our experimental conditions $(T=363 \mathrm{~K}$, $\mathrm{pH}=1$ ). On the contrary, the same experiments performed for $\mathrm{pH}>2$ showed that the dissolution was clearly incongruent due to the significant precipitation of thorium (Table I, Fig. 1 and 2). Indeed, after an initial leaching time, the normalized dissolution rate $R_{\mathrm{L}}(\mathrm{Th})$ strongly decreases, while $R_{\mathrm{L}}(\mathrm{U})$ remains almost constant, whatever the amorphous fraction considered. This observation can be linked directly to the precipitation of tetravalent thorium as TPHPH $\left(\mathrm{Th}_{2}\left(\mathrm{PO}_{4}\right)_{2}\left(\mathrm{HPO}_{4}\right) \cdot \mathrm{H}_{2} \mathrm{O}\right)$ onto the surface of the pellet which is enhanced by the $\mathrm{pH}$ increase. Indeed, in these conditions, the speciation of released phosphates leads to the predominance of $\mathrm{HPO}_{4}{ }^{2-}$ and $\mathrm{PO}_{4}{ }^{3-}$ in solution, which are directly involved in the following equilibrium of precipitation:

$$
\mathrm{Th}_{2}\left(\mathrm{PO}_{4}\right)_{2}\left(\mathrm{HPO}_{4}\right), \mathrm{H}_{2} \mathrm{O} \leftrightarrows 2 \mathrm{Th}^{4+}+2 \mathrm{PO}_{4}^{3-}+\mathrm{HPO}_{4}^{2-}+\mathrm{H}_{2} \mathrm{O}
$$


Consequently, the associated solubility constant is reached more quickly for high $\mathrm{pH}$ values, as shown in Fig. 2: the dissolution is incongruent at high $\mathrm{pH}$ values and congruent in more acidic media. The same conclusions were already made for unirradiated $\beta$-TUPD [36]. Moreover, since the precipitation of TPHPH is endothermic, the Th-precipitation is significantly accelerated by the increase of temperature.

As already reported in literature $[36,48]$, it is important to note that the Thprecipitation significantly affects the release of uranium in the leachate through diffusion phenomena occurring at the surface of the leached samples. Consequently, it was necessary to work far from thermodynamic equilibrium, i.e. at the beginning of the leaching curves for realizing the kinetic study in order to reach more accurate normalized dissolution rate values.

The influence of the amorphous fraction on the normalized dissolution rate is reported in Fig. 3 and Table II. It appears that, for a given leaching time, the higher the amorphous fraction of the sample, the more important the release of actinides. Consequently, the normalized dissolution rates $R_{\mathrm{L}}(\mathrm{U})$, determined from these data (Fig. 4), increase significantly with the amorphous fraction $f_{\mathrm{A}}$ of the sample. This observation can be made for all the leaching conditions. Indeed, whatever the temperature considered $(298 \mathrm{~K}<T<363 \mathrm{~K})$, one to two orders of magnitude between the normalized dissolution rates of the fully amorphized material $R_{\mathrm{L}}(\mathrm{U})_{\text {amorphous }}$ and that of the unirradiated $\beta$-TUPD, $R_{\mathrm{L}}(\mathrm{U})_{\text {unirradiated, }}$ is observed (Table II; Fig. 3 and 4). This result enlightens the increased relative fragility of the chemical bond at the surface of the material due to the damage induced by irradiation. However, despite this increase, the normalized dissolution rate $R_{\mathrm{L}}(\mathrm{U})_{\text {amorphous }}$ remains rather low in comparison to other materials (Table III), which underlines the good chemical durability of the ceramics even after amorphization. 
On the basis of the obtained results, the following empirical relation was deduced between the amorphous fraction and the corresponding normalized dissolution rate (Fig. 4):

$$
R_{\mathrm{L}}\left(f_{\mathrm{A}}\right)=\left[R_{\text {L unirradiated }}\right]^{1-f_{\mathrm{A}}} \times\left[R_{\text {L amorphous }}\right]^{f_{\mathrm{A}}}
$$

This macroscopic observation was realized on the basis of the $R_{\mathrm{L}}$ values and was confirmed through SEM observations of fully amorphized then leached sample (Fig. 5). This cross-section of the sample, recorded on the edge, enabled to observe the irradiated region near the surface and the unirradiated zone. According to the SRIM calculations, the projected range of the $\mathrm{Kr}$ ions is about $72 \mu \mathrm{m}$ in our irradiation conditions. The corresponding thickness under the surface is characterized by an important intergranular porosity. The grain dissociation is more important in the irradiated zone than in the bulk of the material. Such an observation evidences a preferential chemical alteration of the irradiated region compared to the unirradiated phase. This microscopic observation appears to be consistent with the increase of the normalized dissolution rate of the unirradiated material compared to that fully amorphized.

\subsection{Influence of the amorphous fraction $f_{\mathrm{A}}$ on the partial order relative to the proton concentration}

In the aim to evaluate the influence of the amorphous fraction on the $\mathrm{pH}$ influence, some leaching experiments on pre-irradiated samples with different amorphous fractions were performed for various $\mathrm{pH}$ conditions. As previously reported, the saturation conditions occur quickly for $\mathrm{pH}>2$. In order to limit this problem, complementary experiments were driven using dynamic conditions with very flow rates $\left(1-2 \mathrm{~mL} \mathrm{~h}^{-1}\right)$ for $\mathrm{pH}=4$. As a comparison, dynamic experiments were also performed at $\mathrm{pH}=1$ (Fig. 6). We observe the same behaviour than using the static experiments. Indeed, thorium and uranium are leached identically at $\mathrm{pH}=$ 
1, confirming the congruence of the dissolution $(r=1.1)$. On the contrary, thorium is precipitated when leaching in $\mathrm{pH}=4$, leading to a strong decrease of the normalized dissolution rate $(r=32)$. For each amorphous fraction, the logarithm of the normalized dissolution rates always varies linearly versus the $\mathrm{pH}$ of the leachate (Fig. 7). According to Eq. (4), the associated slope, i.e. the partial order relative to the proton concentration, reaches $n=0.34 \pm 0.01$ for the fully amorphized material (compared to $0.37 \pm 0.01$ for unirradiated material [49]). On the basis of this result, the contribution of the proton concentration to the dissolution, i.e. the phenomena occurring at the surface of the leached samples, seem to be almost the same whatever the amorphous fraction considered. On the contrary, the strong influence of the amorphous fraction on the apparent dissolution rate constant $k_{\mathrm{T}}^{\prime}$ observed $\left(\log k_{298 \mathrm{~K}}^{\prime}=-2.13 \pm 0.05\right.$ for $f_{\mathrm{A}}=1$ and $-4.22 \pm 0.02$ for $\left.f_{\mathrm{A}}=0\right)$ is consistent with the one $/$ two orders of magnitude evidenced between the normalized dissolution rates of the fully amorphized and unirradiated samples.

Finally the normalized dissolution rate of a fully amorphized sample in neutral medium ( $\mathrm{pH}=7$ ) was extrapolated from these data. It was found to be about $3.1 \times 10^{-5} \mathrm{~g} \mathrm{~m}^{-2}$ day $^{-1}$ for a fully amorphized $\beta$-TUPD (a previous estimation led to $1.5 \times 10^{-7} \mathrm{~g} \mathrm{~m}^{-2}$ day $^{-1}$ for the unirradiated material [49]). Consequently, the normalized dissolution rate at $298 \mathrm{~K}$ and $\mathrm{pH}=7$ is linked to the amorphous fraction through the expression:

$$
R_{\mathrm{L}}\left(f_{\mathrm{A}}\right)\left(\text { in } \mathrm{g} \mathrm{m}^{-2} \mathrm{day}^{-1}\right)=\left[1.5 \times 10^{-7}\right]^{1-f_{\mathrm{A}}} \times\left[3.1 \times 10^{-5}\right]^{f_{\mathrm{A}}}=1.5 \times 10^{-7} \times[206.7]^{f_{\mathrm{A}}}
$$

\subsection{Influence of the amorphous fraction $f_{\mathrm{A}}$ on the activation energy $E_{\text {app }}$}

In order to evidence the temperature dependence of the normalized dissolution rate of pre-irradiated samples, the activation energy of the dissolution reaction of $\beta$-TUPD was 
determined from data obtained between $298 \mathrm{~K}$ and $363 \mathrm{~K}$ in $10^{-1} \mathrm{M} \mathrm{HNO}_{3}$. Previous studies on unirradiated samples evidenced an apparent activation energy of $49 \pm 4 \mathrm{~kJ} \mathrm{~mol}^{-1}$ [36] close to that reported for several materials and/or other phosphate matrices [50-51]. This value suggests the existence of the formation of an activated complex. Its adsorption energy onto the surface of the sample probably reduces the temperature dependence of the studied reaction.

For each amorphous fraction, the activation energy was determined by plotting of log $\left(R_{\mathrm{L}}(\mathrm{U})\right)$ versus the opposite temperature and taking into account Eq. (5). As shown in Fig. 8, the obtained values for partly amorphized samples are similar $\left(40 \mathrm{~kJ} \mathrm{~mol}^{-1}<E_{\mathrm{app}}<45 \mathrm{~kJ}\right.$ $\left.\mathrm{mol}^{-1}\right)$ to those of unirradiated materials. However, a lower value $\left(20 \pm 4 \mathrm{~kJ} \mathrm{~mol}^{-1}\right)$ is noted for the fully amorphized sample, suggesting the presence of rapid saturation processes which cannot be avoided due to higher normalized dissolution rates. This phenomenon leads to underestimate values of $E_{\text {app }}$.

More generally, the activation energy is smaller than the energy required for the breaking of covalent bonds $\left(160-400 \mathrm{~kJ} \mathrm{~mol}^{-1}\right)$ probably due to adsorption phenomena.

As a summary, a pre-irradiation of the samples does not affect the kinetic parameters (activation energy, partial order related to proton concentration) which clearly indicates that the main steps of the dissolution mechanism are unmodified, whatever the amorphous ratio of the solid. In all cases, the value indicates that the dissolution is not controlled by diffusion processes in the first part of the dissolution curves (which are associated to activation energy smaller than $21 \mathrm{~kJ} \mathrm{~mol}^{-1}$ ) [52].

\subsection{Influence of the irradiation stopping power on the normalized dissolution rate}


Previously presented results were dedicated to samples pre-irradiated with $840-\mathrm{MeV}$ $\mathrm{Kr}$ ions. In order to evidence the incidence of the nature of interactions between the ions and the solid, some leaching tests were also driven on samples previously irradiated with 410$\mathrm{MeV} \mathrm{S}$ and 4-MeV Au. In such experiments, the nature of interactions ions/sample differs. Interactions are quantified by the "stopping power" $S$, which represents the local energy loss of the particle in the material $\left(\mathrm{MeV} \mu \mathrm{m}^{-1}\right)$. For high energy beams $(840-\mathrm{MeV} \mathrm{Kr}, 410-\mathrm{MeV}$ S), the incident particles mainly lose their energy in the target-sample through electronic interactions (through excitation and ionisation processes). Nuclear interactions (ballistic impacts, atomic displacements) are negligible at high energy but predominant at low energy [23]. For 4-MeV Au ions irradiations, electronic and nuclear contributions to the stopping power $\left(S_{\mathrm{e}}\right.$ and $\left.S_{\mathrm{n}}\right)$ are equivalent (Table IV).

The variation of $R_{\mathrm{L}}(\mathrm{U})$ with the amorphous fraction for the various irradiation conditions is presented in Fig.9. The comparison of the results obtained for $\mathrm{Kr}$ and $\mathrm{S}$ ions (i.e. for a negligible nuclear stopping power $S_{\mathrm{n}}$ ) evidences that $R_{\mathrm{L}}(\mathrm{U})$ is significantly dependent on the $S_{\mathrm{e}}$ value. Indeed, the influence of the amorphous fraction becomes more significant when increasing the electronic contribution. On the contrary, the nuclear contribution does not seem to play any important role on the $R_{\mathrm{L}}(\mathrm{U})$ variation as it is evidenced by the comparable results obtained for $\mathrm{Au}$ and $\mathrm{S}$ pre-irradiations: both only differ through the $S_{\mathrm{n}}$ value. Thus the normalized dissolution rate is more sensitive to the electronic contribution of the stopping power. The presence of electronic damage induced by irradiation influences the chemical durability of the material in a more significant way than the nuclear ones. This not yet fully understood phenomenon is certainly related to the different microstructures of the materials generated by irradiation in the electronic and nuclear regimes. This important aspect of the nature of the radiation damage on the leaching consequences deserves further studies based on 
techniques able to provide information on the short and medium range atomic order (e.g. EXAFS spectroscopy...).

The SEM micrograph of fully amorphized under pre-irradiation then leached samples (Fig. 5) also confirms this phenomenon. Indeed, the alteration is found to be more important at the end of the particle path (in the last micrometers of the irradiated thickness before the unirradiated zone) than at the beginning of the path. This ending-zone matches with the localization of the "Bragg peak" which corresponds to the maximum of the electronic stopping power $S_{\mathrm{e}}$. In other words, the irradiated phase appears to be more altered when the electronic stopping power is high which is consistent with the results summarized in Fig. 9.

\section{Conclusion}

The effects of the pre-irradiation on the kinetics of $\beta$-TUPD dissolution were examined in various leaching conditions (temperature, $\mathrm{pH}$, flow rate). This study emphasizes the effect of the amorphous fraction on the normalized dissolution rate, which is increased from one to two orders of magnitude between the unirradiated $\left(f_{\mathrm{A}}=0\right)$ to the fully amorphized $\left(f_{\mathrm{A}}=1\right)$ materials. From the obtained data, an exponential relation between the normalized dissolution rate $R_{\mathrm{L}}(\mathrm{U})$ and the amorphous fraction $f_{\mathrm{A}}$ was proposed. However, despite the increase of the normalized dissolution rate after irradiation, amorphized $\beta$-TUPD remains highly resistant to alteration $\left(3.1 \times 10^{-5} \mathrm{~g} \mathrm{~m}^{-2}\right.$ day $^{-1}$ for $\mathrm{pH}=7$ and $\left.T=298 \mathrm{~K}\right)$.

The effect of the amorphous fraction on the parameters driving the kinetics of dissolution was also examined. The pre-irradiation of the sample has no influence on the partial order $n$ relative to the proton and on the activation energy $E_{\text {app }}$ of the reaction of dissolution. 
These results were obtained far from equilibrium conditions. However, the precipitation of thorium was always accelerated when increasing the leaching time, the $\mathrm{pH}$ or the temperature due to the more rapid reach of the saturation conditions. The formation of neoformed phase onto the surface of the sample leads to a slowing down of the uranium release in the leachate consequently to diffusion or passivation phenomena. In these conditions, it appears interesting to examine and characterize the consequences of irradiation on the nature and the formation of neoformed phases. This aspect will be reported in a forthcoming publication.

\section{Acknowledgements}

This work was financially and scientifically supported by the French Research Group NOMADE (GdR 2023, CNRS / CEA / COGEMA). The authors are very grateful to Jérôme Ritt from IRSN, Fontenay-Aux-Roses (France) for his support during ICP-MS measurements, and to Renaud Podor and Alain Kohler for their assistance during the SEM experiments. 


\section{Table caption}

Table I Normalized dissolution rates $R_{\mathrm{L}}(\mathrm{U})$ and $R_{\mathrm{L}}(\mathrm{Th})\left(\mathrm{g} \mathrm{m}^{-2} \mathrm{day}^{-1}\right)$ of $\beta$-TUPD in different media at the beginning ( $t=0$, congruent dissolution) and at long leaching times (incongruent dissolution). $r$ corresponds to the $R_{\mathrm{L}}(\mathrm{U}) / R_{\mathrm{L}}(\mathrm{Th})$ ratio.

Table II Normalized dissolution rates $R_{\mathrm{L}}(\mathrm{U})\left(\mathrm{g} \mathrm{m}^{-2}\right.$ day $\left.{ }^{-1}\right)$ of $\beta$-TUPD for various amorphous fractions. $\rho$ represents the ratio $R_{\mathrm{L}}(\mathrm{U}) / R_{\mathrm{L}}(\mathrm{U})_{\text {unirradiated }}$.

Table III Normalized dissolution rates $\left(\mathrm{g} \mathrm{m}^{-2}\right.$ day $\left.^{-1}\right)$ of crystallized and amorphous phases reported for various materials $\left(\mathrm{H}_{2} \mathrm{O}, T=363 \mathrm{~K}\right)$.

Table IV Electronic and nuclear stopping power values of ions in $\beta$-TUPD sintered samples for various irradiation conditions. 
Table I

\begin{tabular}{|c|c|c|c|c|c|c|c|}
\hline \multirow{2}{*}{ Leaching conditions } & \multirow{2}{*}{$f_{\mathrm{A}}$} & \multicolumn{3}{|c|}{ Initial $R_{\mathrm{L}}(\mathbf{i})\left(\mathrm{g} \mathrm{m}^{-2} \mathrm{day}^{-1}\right)$} & \multicolumn{3}{|c|}{ Long-term $R_{\mathrm{L}}(\mathrm{i})\left(\mathrm{g} \mathrm{m}^{-2}\right.$ day $\left.^{-1}\right)$} \\
\hline & & $\mathbf{U}$ & Th & $r$ & $\mathbf{U}$ & Th & $r$ \\
\hline \multirow{4}{*}{$\begin{array}{c}T=298 \mathrm{~K} \\
10^{-1} \mathrm{M} \mathrm{HNO}_{3}\end{array}$} & 0 & $(2.5 \pm 0.3) \times 10^{-5}$ & $(2.4 \pm 0.3) \times 10^{-5}$ & 1 & $(2.5 \pm 0.3) \times 10^{-5}$ & $(2.4 \pm 0.3) \times 10^{-5}$ & 1 \\
\hline & 0.2 & $(9.9 \pm 1.0) \times 10^{-5}$ & $(7.0 \pm 0.8) \times 10^{-5}$ & 1.4 & $(9.9 \pm 1.0) \times 10^{-5}$ & $(7.0 \pm 0.8) \times 10^{-5}$ & 1.4 \\
\hline & 0.6 & $(2.1 \pm 0.2) \times 10^{-4}$ & $(4.6 \pm 0.5) \times 10^{-4}$ & 0.5 & $(2.1 \pm 0.2) \times 10^{-4}$ & $(4.6 \pm 0.5) \times 10^{-4}$ & 0.5 \\
\hline & 1 & $(2.3 \pm 0.3) \times 10^{-3}$ & $(1.2 \pm 0.2) \times 10^{-3}$ & 1.9 & $(2.3 \pm 0.3) \times 10^{-3}$ & $(1.2 \pm 0.2) \times 10^{-3}$ & 1.9 \\
\hline \multirow{5}{*}{$\begin{array}{c}T=363 \mathrm{~K} \\
10^{-1} \mathrm{M} \mathrm{HNO}_{3}\end{array}$} & 0 & $(1.4 \pm 0.2) \times 10^{-4}$ & $(1.0 \pm 0.1) \times 10^{-4}$ & 1.4 & $(1.4 \pm 0.2) \times 10^{-4}$ & $(1.0 \pm 0.1) \times 10^{-4}$ & 1.4 \\
\hline & 0.2 & $(2.9 \pm 0.3) \times 10^{-3}$ & $(1.5 \pm 0.2) \times 10^{-3}$ & 1.9 & $(1.8 \pm 0.2) \times 10^{-4}$ & $(1.7 \pm 0.2) \times 10^{-5}$ & 11 \\
\hline & 0.6 & $(6.6 \pm 0.7) \times 10^{-3}$ & $(7.5 \pm 0.8) \times 10^{-3}$ & 0.9 & $(1.0 \pm 0.1) \times 10^{-3}$ & N.D. & N.D. \\
\hline & 0.8 & $(3.0 \pm 0.3) \times 10^{-3}$ & $(6.0 \pm 0.6) \times 10^{-3}$ & 0.5 & $(1.1 \pm 0.1) \times 10^{-3}$ & $<10^{-5}$ & $>100$ \\
\hline & 1 & $(9.9 \pm 1.0) \times 10^{-3}$ & $(1.8 \pm 0.2) \times 10^{-2}$ & 0.6 & $(1.1 \pm 0.1) \times 10^{-3}$ & $<10^{-4}$ & $>10$ \\
\hline \multirow{4}{*}{$\begin{array}{c}T=298 \mathrm{~K} \\
10^{-4} \mathrm{M} \mathrm{HNO}_{3}\end{array}$} & 0 & $(1.2 \pm 0.1) \times 10^{-6}$ & N.D. & N.D. & $(2.5 \pm 0.3) \times 10^{-7}$ & $<2 \times 10^{-8}$ & $>12$ \\
\hline & 0.2 & $(3.7 \pm 0.4) \times 10^{-6}$ & $(7.7 \pm 0.8) \times 10^{-6}$ & 0.5 & $(2.0 \pm 0.2) \times 10^{-6}$ & $<2 \times 10^{-8}$ & $>100$ \\
\hline & 0.8 & $(5.4 \pm 0.5) \times 10^{-6}$ & $<2 \times 10^{-8}$ & $>100$ & $(5.4 \pm 0.5) \times 10^{-6}$ & $<2 \times 10^{-8}$ & $>100$ \\
\hline & 1 & $(2.9 \pm 0.3) \times 10^{-4}$ & $(2.5 \pm 0.3) \times 10^{-6}$ & 116 & $(2.9 \pm 0.3) \times 10^{-4}$ & $(2.5 \pm 0.3) \times 10^{-6}$ & 116 \\
\hline
\end{tabular}

${ }^{*}$ The data reported in italic underline incongruent conditions of dissolution. 


\section{Table II}

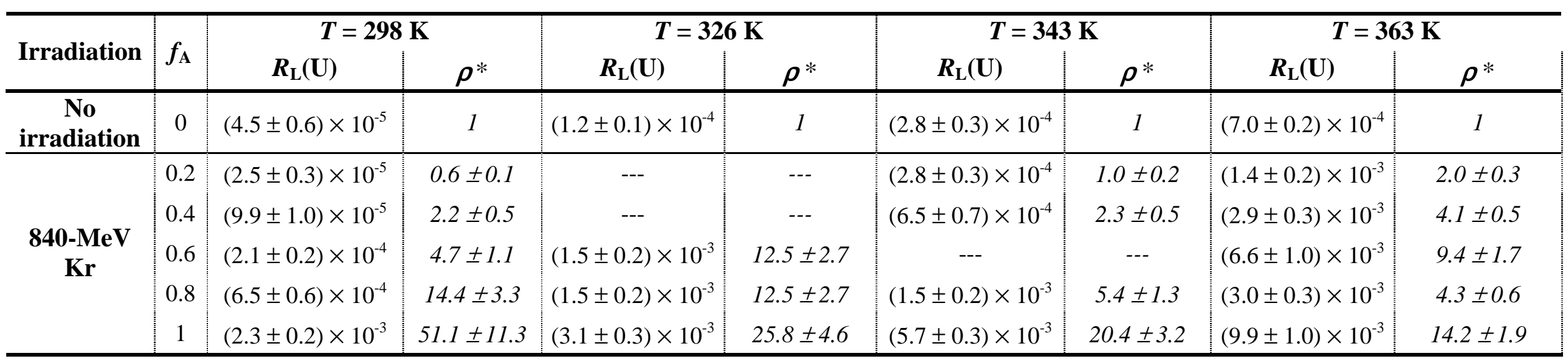

${ }^{*} \rho=R_{\mathrm{L}}(\mathrm{U}) / R_{\mathrm{L}}(\mathrm{U})_{\text {unirradiated }}$ 


\section{Table III}

\begin{tabular}{|c|c|c|c|c|}
\hline \multirow[b]{2}{*}{ Material } & \multicolumn{2}{|c|}{ Normalized dissolution rate $R_{\mathrm{L}}\left(\mathrm{g} \mathrm{m}^{-2}\right.$ day $\left.^{-1}\right)$} & \multirow[b]{2}{*}{$\rho_{A} * *$} & \multirow[b]{2}{*}{ Reference } \\
\hline & $\begin{array}{l}\text { Crystalline phase } \\
\qquad\left(f_{\mathrm{A}}=0\right)\end{array}$ & $\begin{array}{l}\text { Fully amorphized phase } \\
\qquad\left(f_{\mathrm{A}}=1\right)\end{array}$ & & \\
\hline Monazite & $1 \times 10^{-3}$ & $1 \times 10^{-2}$ & 10 & [53] \\
\hline Zirconolite & $2 \times 10^{-3}$ & $3 \times 10^{-2}$ & 15 & {$[54]$} \\
\hline Pyrochlore & $9 \times 10^{-3}$ & $4.5 \times 10^{-1}$ & 50 & [54] \\
\hline$\beta$-TUPD & $5 \times 10^{-7}$ & $4 \times 10^{-5} *$ & 80 & {$[49$, this work $]$} \\
\hline Apatite & $3.5 \times 10^{-3}$ & $4.2 \times 10^{-1}$ & 120 & [54] \\
\hline Zircon & $5 \times 10^{-5}$ & $8 \times 10^{-3}$ & 160 & [55] \\
\hline
\end{tabular}


Table IV

\begin{tabular}{lcc}
\hline \multicolumn{1}{c}{ Ion beam } & \multicolumn{2}{c}{ Stopping power $\left(\mathrm{MeV} \boldsymbol{\mu m}^{-\mathbf{1}}\right)$} \\
& Electronic $\left(\boldsymbol{S}_{\mathbf{e}}\right)$ & $\operatorname{Nuclear}\left(\boldsymbol{S}_{\mathbf{n}}\right)$ \\
\hline 840-MeV Kr & 10.4 & $7 \times 10^{-3}$ \\
410-MeV S & 2.5 & $10^{-3}$ \\
4-MeV Au & 2.6 & 2.5 \\
\hline
\end{tabular}




\section{Figure caption}

Figure 1 Evolution of the normalized leachings $N_{\mathrm{L}}(\mathrm{U})(\bullet)$ and $N_{\mathrm{L}}(\mathrm{Th})(\circ)$ during the dissolution of $\beta$-TUPD sintered samples in $10^{-1} \mathrm{M} \mathrm{HNO}_{3}$ for unirradiated $\left(f_{\mathrm{A}}=0\right)$ and fully amorphized $\left(f_{\mathrm{A}}=1\right)$ samples. The dotted zone corresponds to the first 60 days of leaching.

Figure 2 Variation of $r=R_{\mathrm{L}}(\mathrm{U}) / R_{\mathrm{L}}(\mathrm{Th})$ versus the $\mathrm{pH}$ value at $298 \mathrm{~K}$ for unirradiated $\left(f_{\mathrm{A}}\right.$ $=0)(\bullet)$ and fully amorphized $\left(f_{\mathrm{A}}=1\right)(\square) \beta$-TUPD samples.

Figure 3 Evolution of the normalized leaching $N_{\mathrm{L}}(\mathrm{U})$ during the dissolution of $\beta$-TUPD sintered samples in $10^{-1} \mathrm{M} \mathrm{HNO}_{3}$ for several initial amorphous fractions $f_{\mathrm{A}}(\mathrm{A})$. The zoom on the first 70 days evidences the variation of the associated normalized dissolution rates $R_{\mathrm{L}}(\mathrm{U})$ for the corresponding amorphous fractions (B) $: R_{\mathrm{L}}(\mathrm{U})=(7.0 \pm 0.2) \times 10^{-4}(\mathrm{a}),(1.4 \pm 0.2) \times 10^{-3}(\mathrm{~b}),(2.9 \pm 0.3) \times 10^{-3}(\mathrm{c}),(3.0 \pm$ $0.3) \times 10^{-3}(\mathrm{~d}),(9.9 \pm 1.0) \times 10^{-3}(\mathrm{e}) \mathrm{g} \mathrm{m}^{-2} \mathrm{day}^{-1}$.

Figure 4 Variation of the normalized dissolution rate $R_{\mathrm{L}}(\mathrm{U})$ versus the amorphous fraction $f_{\mathrm{A}}$ during the dissolution of $\beta$-TUPD sintered samples in $10^{-1} \mathrm{M} \mathrm{HNO}_{3}$. The dotted lines represent the fit obtained considering Eq.(7) (a) and associated variation of the ratio $\rho=R_{\mathrm{L}}(\mathrm{U}) / R_{\mathrm{L}}(\mathrm{U})_{\text {unirradiated }}$ versus the amorphous fraction $f_{\mathrm{A}}$ for $T=298 \mathrm{~K}(\square)$ and $T=363 \mathrm{~K}(\mathbf{\square})(\mathrm{b})$.

Figure 5 SEM observation of a leached pre-irradiated $\beta$-TUPD sintered sample (840-MeV $\left.\mathrm{Kr}, f_{\mathrm{A}}=1 ; 10^{-1} \mathrm{M} \mathrm{HNO}_{3}, T=363 \mathrm{~K}\right)$. Observation of the various alteration zones between unirradiated and irradiated zones.

Figure 6 Evolution of the normalized leachings $N_{\mathrm{L}}(\mathrm{U})$ (solid symbols) and $N_{\mathrm{L}}(\mathrm{Th})$ (open symbols) (a) and associated evolution of the cumulative normalized leaching (b) when dissolving fully amorphized $\beta$-TUPD sintered samples $\left(f_{\mathrm{A}}=1\right)$ (dynamic conditions, $10^{-1} \mathrm{M} \mathrm{HNO}_{3}(\bullet / O)$ or $\left.10^{-4} \mathrm{M} \mathrm{HNO}_{3}(\mathbf{\Delta} / \triangle), T=298 \mathrm{~K}\right) . r$ corresponds to the ratio $R_{\mathrm{L}}(\mathrm{U}) / R_{\mathrm{L}}(\mathrm{Th})$. 
Figure 7 Variation of $\log \left(R_{\mathrm{L}}(\mathrm{U})\right)$ versus the $\mathrm{pH}$ value at $298 \mathrm{~K}$ for unirradiated $\left(\mathrm{O}: f_{\mathrm{A}}=\right.$ $0)$ and fully amorphized $\beta$-TUPD samples $\left(\bullet: f_{\mathrm{A}}=1\right)$.

Figure 8 Variation of the activation energy of the dissolution reaction of $\beta$-TUPD versus the amorphous fraction $f_{\mathrm{A}}$.

Figure 9 Variation of the normalized dissolution rate $R_{\mathrm{L}}(\mathrm{U})$ versus the amorphous fraction $f_{\mathrm{A}}$ during the dissolution of $\beta$-TUPD sintered samples in $10^{-1} \mathrm{M} \mathrm{HNO}_{3}$ for three kinds of irradiation experiments (840-MeV Kr, 410-MeV S, 4-MeV Au). The dotted lines correspond to the fitting results obtained taking into account Eq.(7). 


\section{Figure 1}

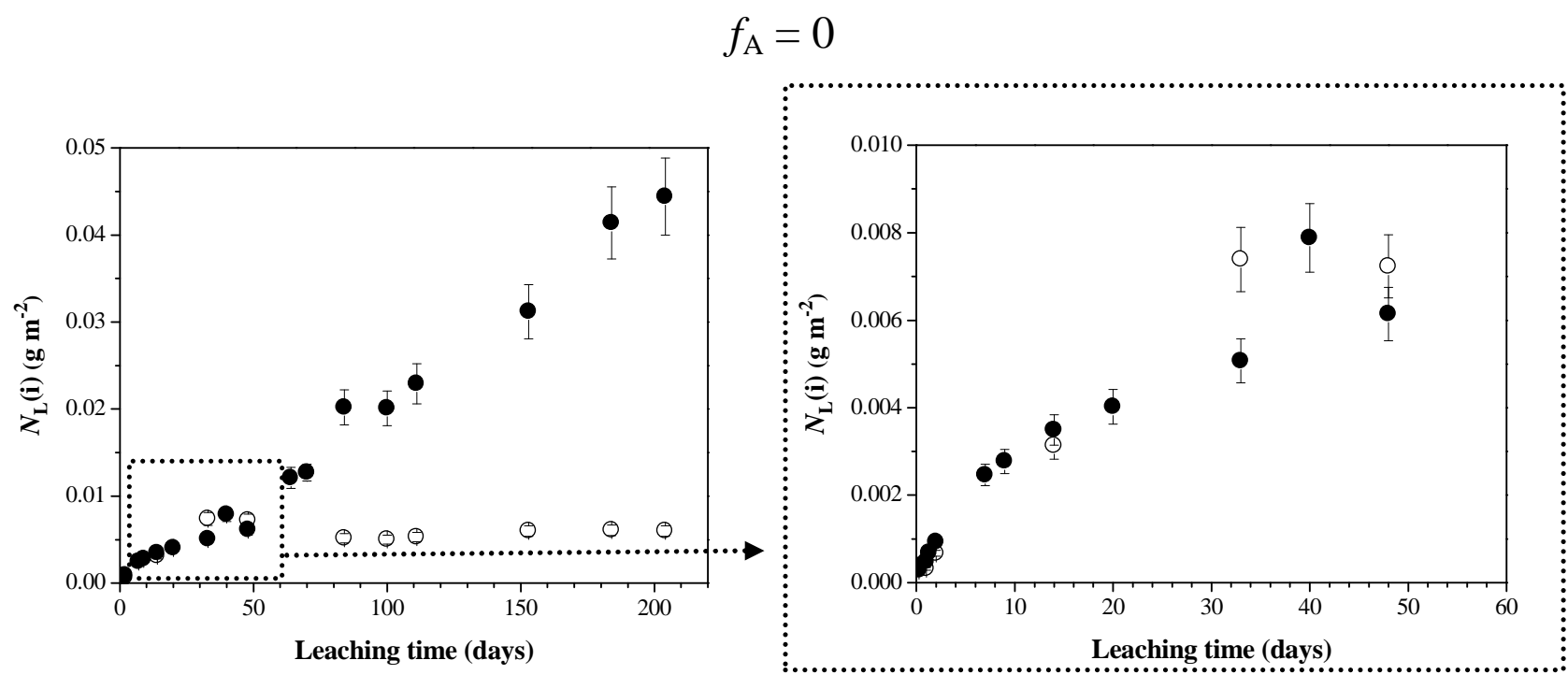

$$
f_{\mathrm{A}}=1
$$
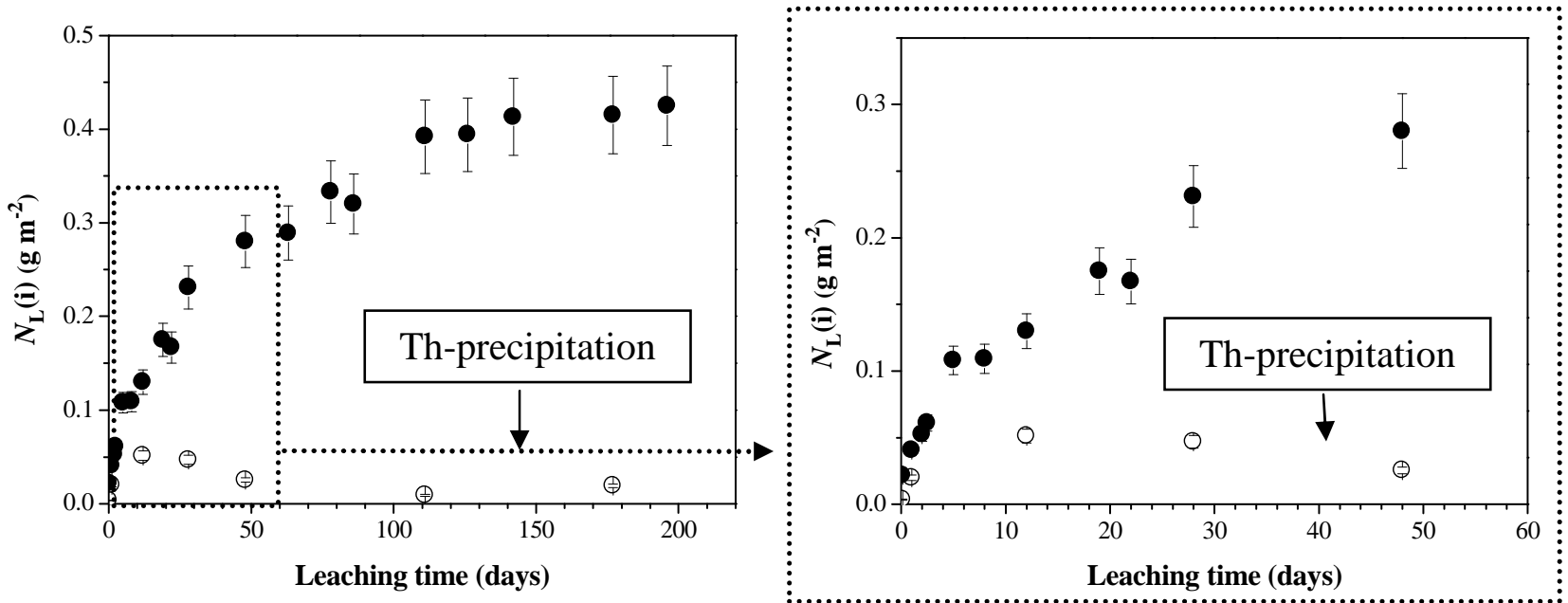
Figure 2

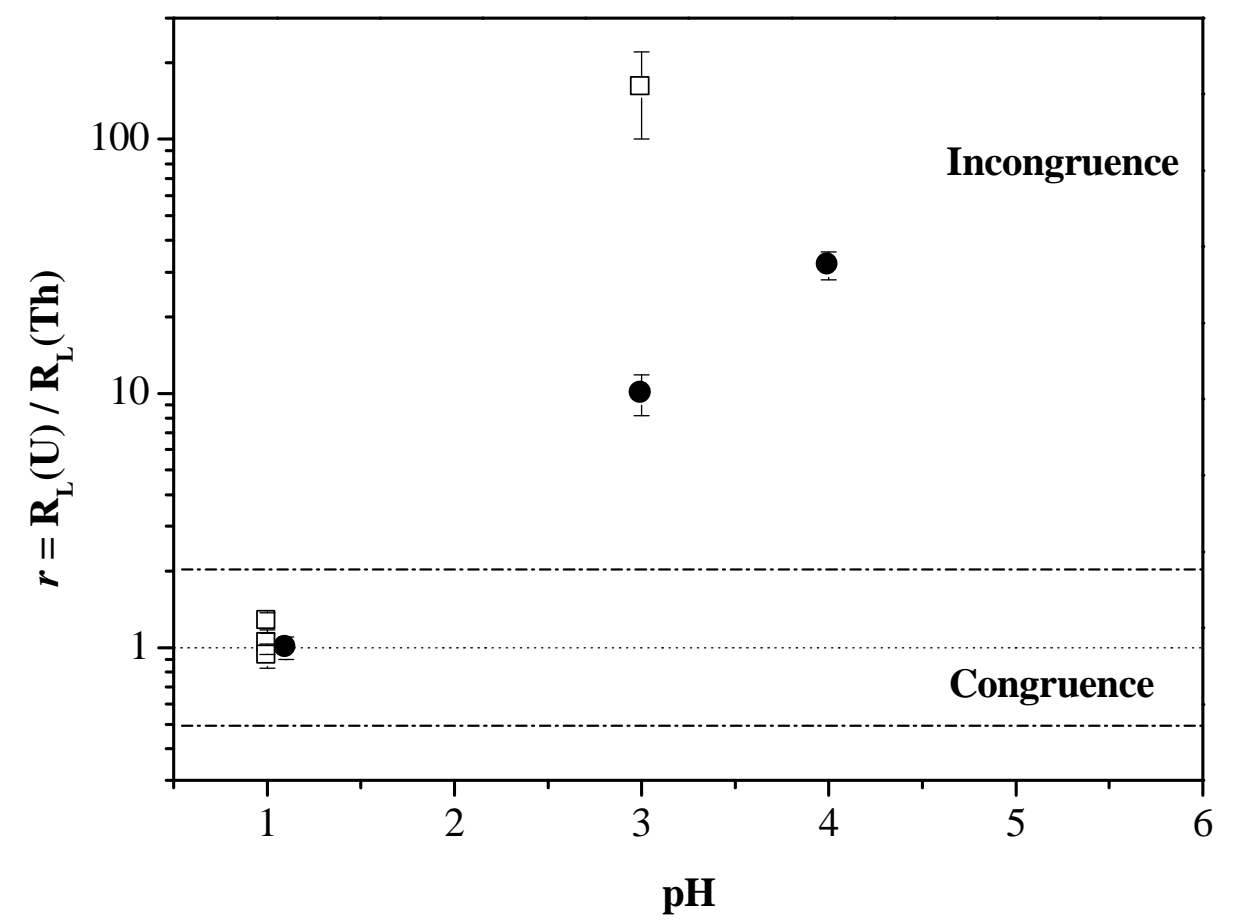




\section{Figure 3}

(A)

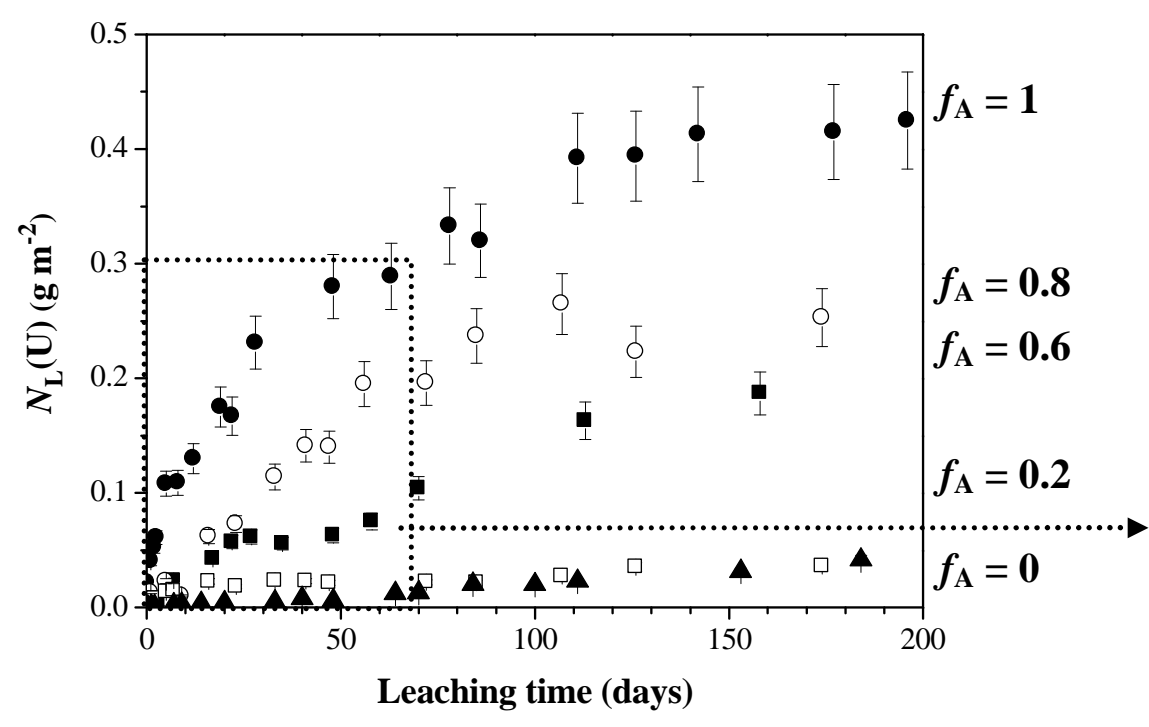

(B)

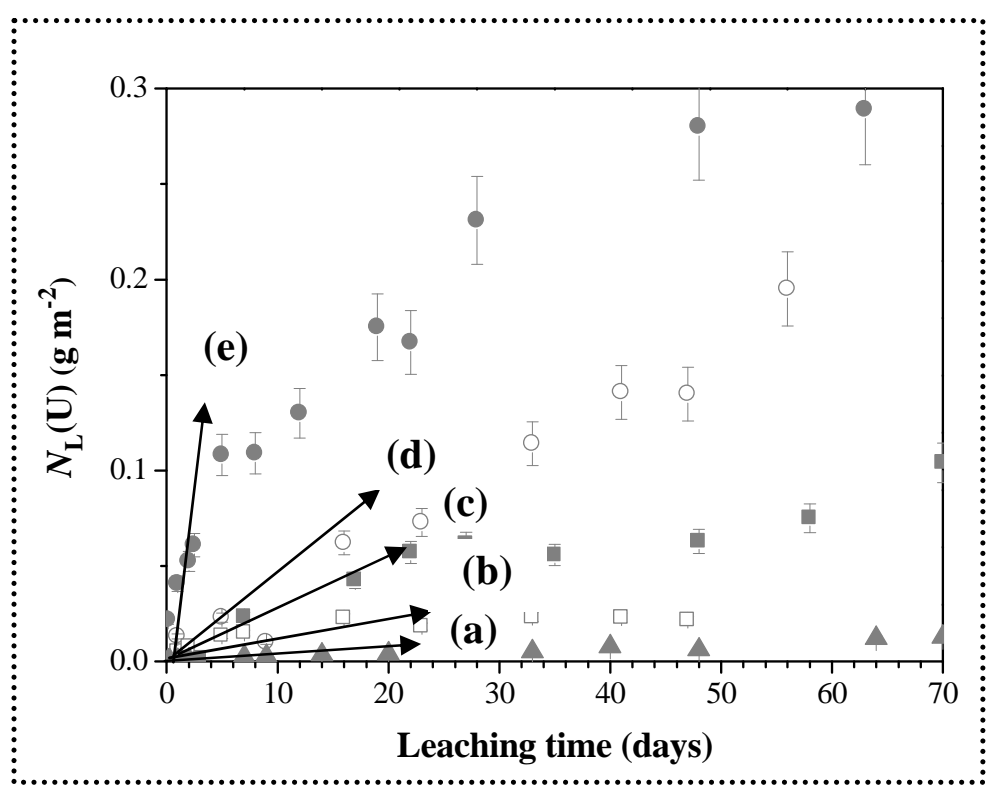




\section{Figure 4}

(a)

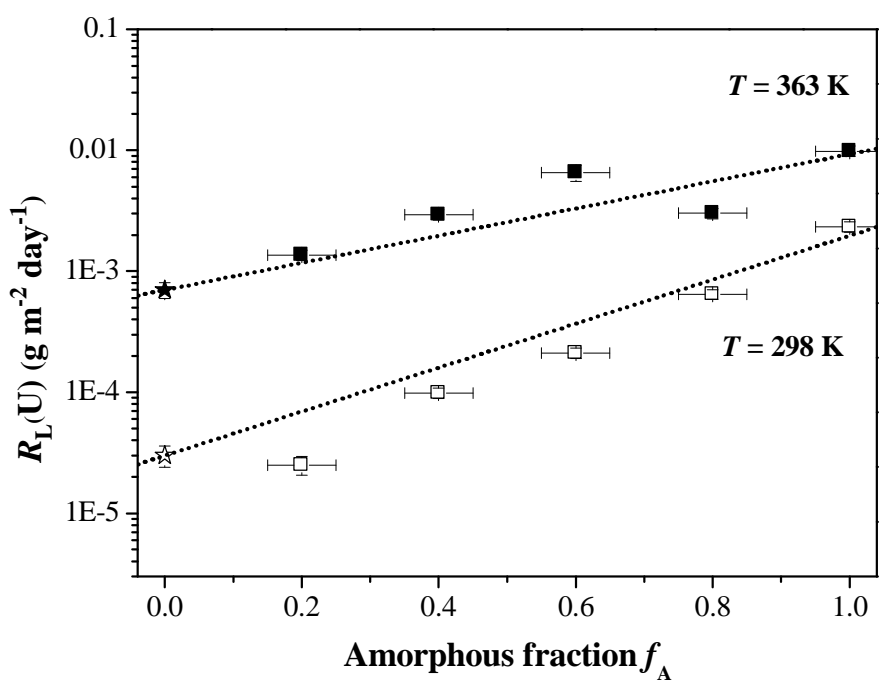

(b)

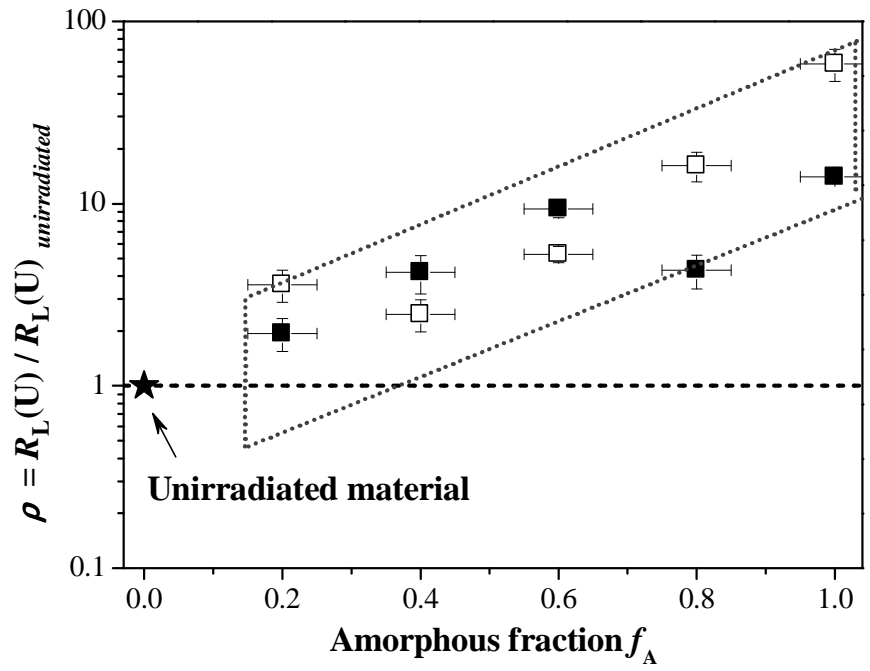


Figure 5

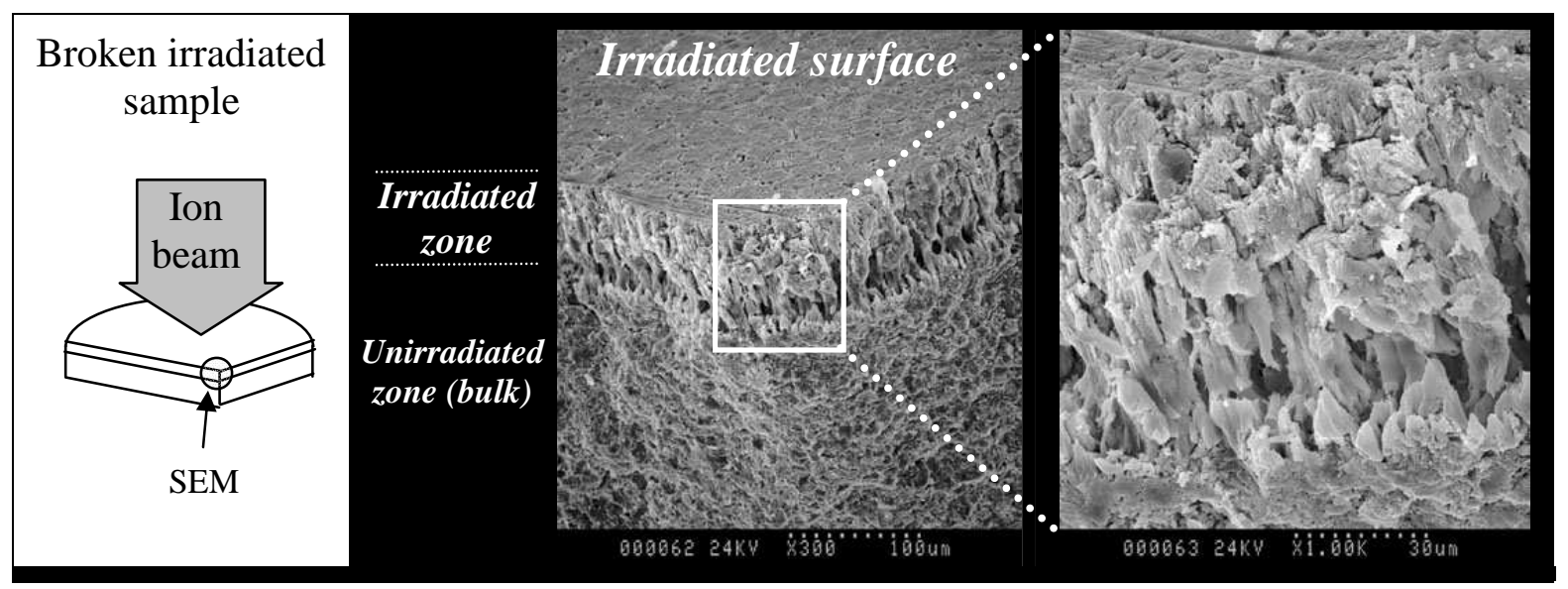


Figure 6

(a)

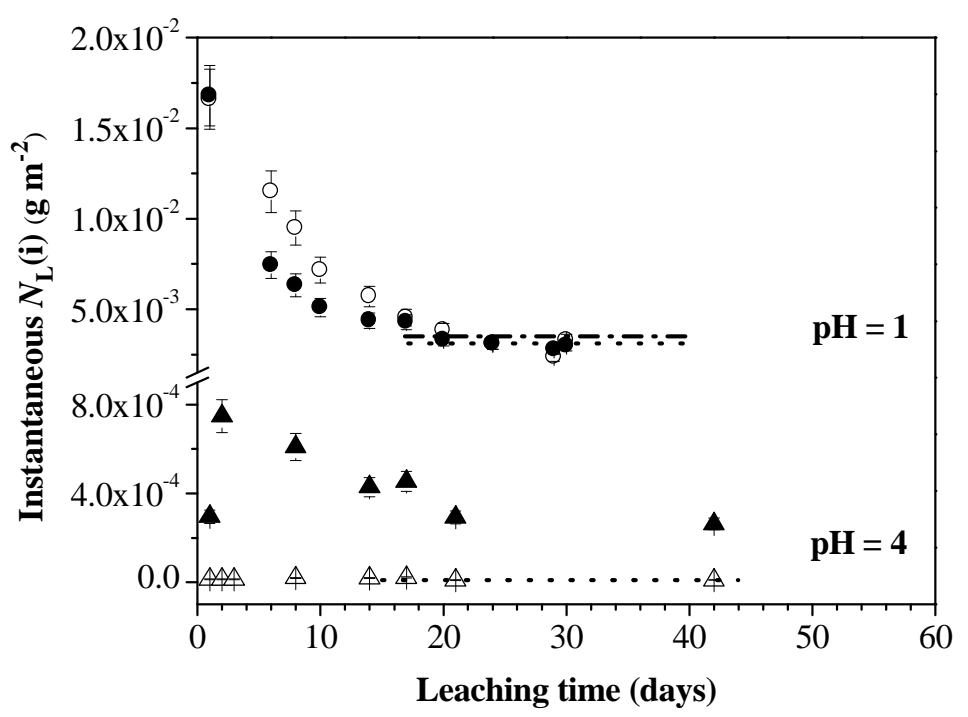

(b)

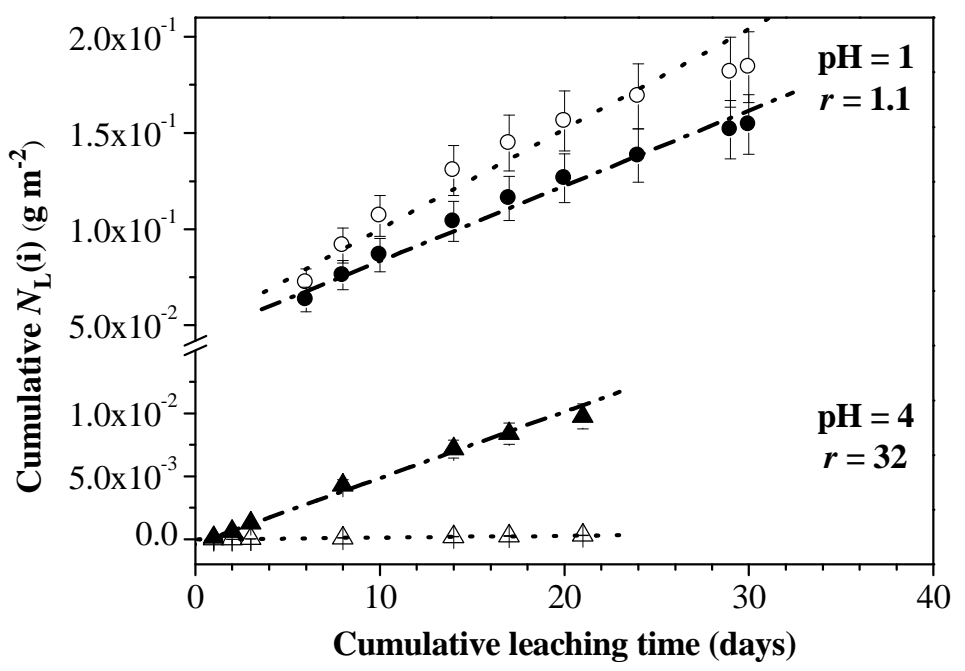


Figure 7

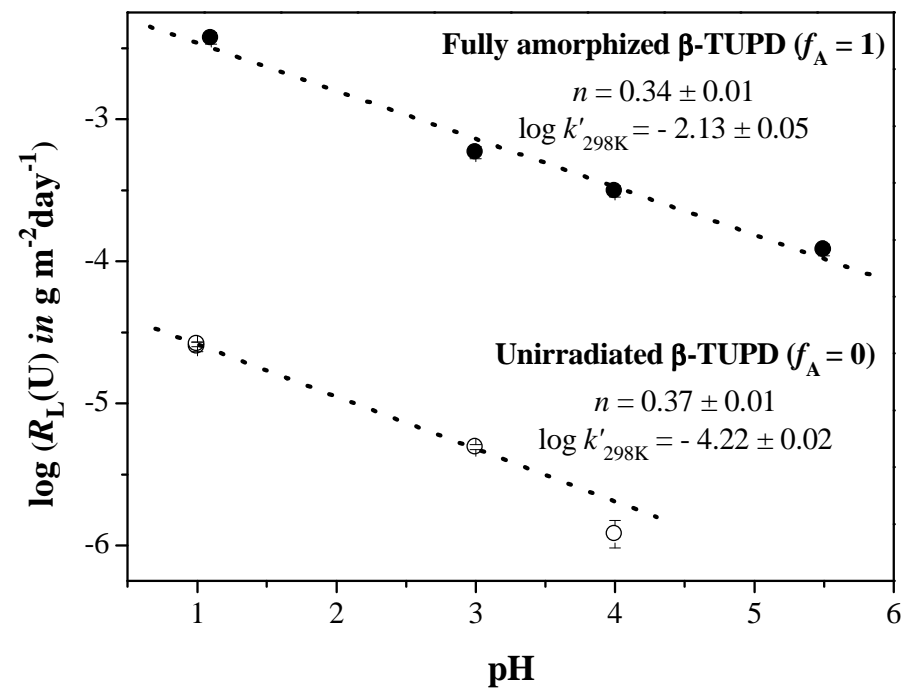


Figure 8

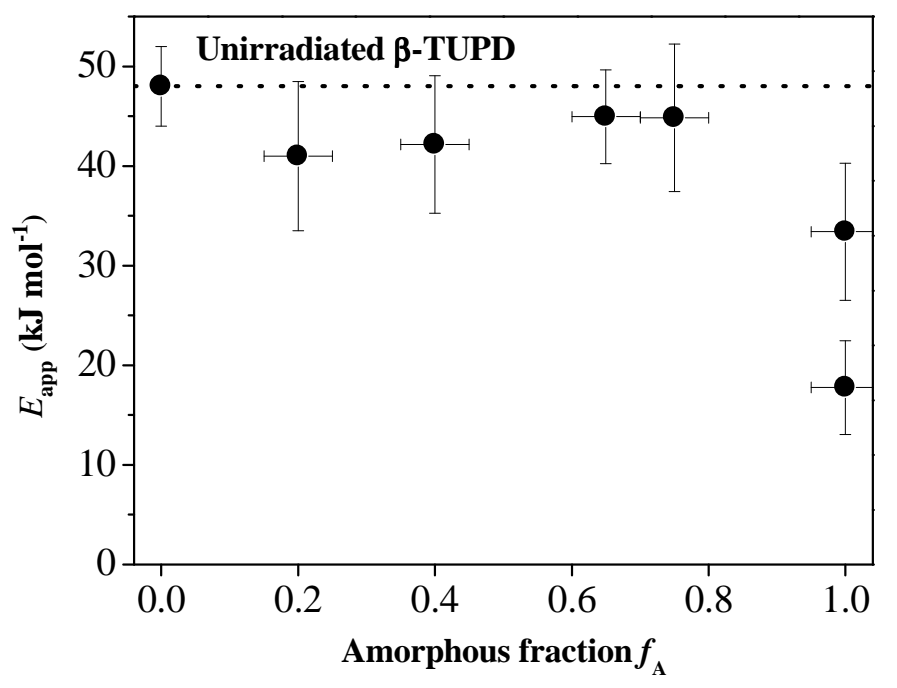


Figure 9

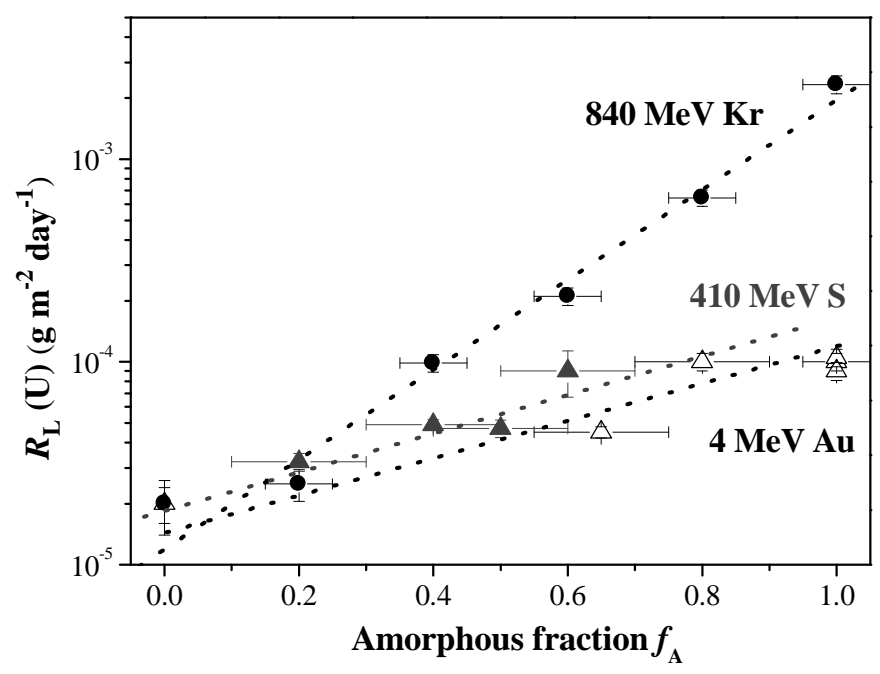




\section{References}

[1] J.C. André, C.R. Acad. Sci. Paris - IIA 333 (2001) 835.

[2] B.D. Begg, E.R. Vance, R.A. Day, M. Hambley, S.D. Conradson, in "Scientific Basis for Nuclear Waste Management XX”, Eds. W.J. Gray \& I.R. Triay 465 (1997) 352.

[3] C. Guy, F. Audubert, J.E. Lartigue, C. Latrille, T. Advocat, C. Fillet, C. R. Acad. Sci. Paris 3 (2002) 827.

[4] T. Advocat, C. Fillet, J. Marillet, G. Leturcq, J.M. Boubals, A. Bonnetier, in "Scientific Basis for Nuclear Waste Management XXI”, Eds. I.G. McKinley, C. McCombie 506 (1998) 55.

[5] J. Carpena, F. Audubert, D. Bernache, L. Boyer, B. Donazzon, J.L. Lacout, N. Senamaud, in "Scientific Basis for Nuclear Waste Management XXI”, Eds. I.G. McKinley, C. McCombie 506 (1998) 543.

[6] R. Bros, J. Carpena, V. Sere, A. Beltritti, Radiochim. Acta 74 (1996) 277.

[7] L.A. Boatner, B.C. Sales, in : "Radioactive Waste Forms for the Future", W. Lutze and R.C. Ewing (Eds.) North-Holland Physics Publishing Amsterdam, 1998, 495.

[8] J.M. Montel, J.L. Devidal, D. Avignant, Chem. Geol. 191 (2002) 89.

[9] R. Podor, M. Cuney, Am. Miner. 82 (1997) 765.

[10] R. Podor, M. Cuney, C. Nguyen Trung, Am. Miner. 80 (1995) 1261.

[11] A. Meldrum, L.A. Boatner, W.J. Weber, R.C. Ewing, Geochim. Cosmochim. Acta 62 (1998) 2509.

[12] M.M. Abraham, L.A. Boatner, T.C. Quinby, D.K. Thomas, M. Rappaz, in : "Radioactive Waste Management", 1980, 1, 181.

[13] O. Terra, N. Clavier, N. Dacheux, R. Podor, New J. Chem. 27 (2003) 957.

[14] P. Benard, V. Brandel, N. Dacheux, S. Jaulmes, S. Launay, C. Lindecker, M. Genet, D. Louër, M. Quarton, Chem. Mater. 8 (1996) 181.

[15] V. Brandel, N. Dacheux, M. Genet, Radiokhimiya 43 (2001) 16.

[16] N. Dacheux, R. Podor, V. Brandel, M. Genet, J. Nucl. Mater. 252 (1998) 179.

[17] N. Dacheux, A.C. Thomas, V. Brandel, M. Genet, J. Nucl. Mater. 257 (1998) 108.

[18] N. Clavier, N. Dacheux, R. Podor, Inorg. Chem. 45 (2006) 220.

[19] A.C. Robisson, N. Dacheux, J. Aupiais, J. Nucl. Mater. 306 (2002) 134.

[20] N. Dacheux, A.C. Thomas, B. Chassigneux, E. Pichot, V. Brandel, M. Genet, in "Scientific Basis for Nuclear Waste Management XXII”, Eds. I.G. McKinley C. McCombie, 556 (1999) 85.

[21] A.C. Thomas, in "Etude de la dissolution du phosphate diphosphate de thorium : aspect cinétique, aspect thermodynamique", PhD Thesis of Université Paris-Sud-11, Orsay, IPNO-T-00.09, 2000.

[22] W.J. Weber, R.C. Ewing, C.R.A. Catlow, T. Diaz De La Rubia, L.W. Hobbs, C. Kinoshita, Hj. Matzke, A.T. Motta, M. Nastasi, E.H.K. Salje, E.R. Vance, S.J. Zinkle, J. Mater. Res. 13 (1998) 1434.

[23] L. Thomé, F. Garrido, Vaccum 63 (2001) 619.

[24] D. Begg, N.J. Hess, W.J. Weber, R. Devanathan, J.P. Icenhower, S. Thevuthasan, B.P. McGrail, J. Nucl. Mater. 288 (2001) 208.

[25] V. Brandel, N. Dacheux, M. Genet, R. Podor, J. Solid St. Chem. 159 (2001) 139.

[26] N. Dacheux, N. Clavier, G. Wallez, V. Brandel, J. Emery, M. Quarton, M. Genet, Mat. Res. Bull. 40 (2005) 2225.

[27] N. Clavier, N. Dacheux, G. Wallez, M. Quarton, J. Nucl. Mater., 352 (2006) 209.

[28] N. Dacheux, B. Chassigneux, V. Brandel, P. Le Coustumer, M. Genet, G. Cizeron, Chem. Mater. 14 (2002) 2953.

[29] N. Clavier, N. Dacheux, P. Martinez, E. du Fou de Kerdaniel, L. Aranda, R. Podor, Chem. Mater. 16 (2004) 3357. 
[30] P. Frugier, C. Martin, I. Ribet, T. Advocat, S. Gin, J. Nucl. Mater. 346 (2005) 194.

[31] C. Tamain, F. Garrido, L. Thomé, N. Dacheux, A. Özgümüs, A. Benyagoub, J. Nucl. Mater. (submitted)

[32] C. Tamain, in "Etude des effets d'irradiation sur le Phosphate Diphosphate de Thorium ( $\beta$-PDT) ; conséquences sur la durabilité chimique", PhD Thesis of Université Paris-Sud-11, IPNO-T-05-09, 2005.

[33] A.C. Thomas, N. Dacheux, P. Le Coustumer, V. Brandel, M. Genet, J. Nucl. Mater. 295 (2001) 249.

[34] J.F. Ziegler, JP. Biersack, U. Littmark. In: Ziegler JF, Editor. The Stopping and range of ions in solids, Vol.1. New York: Pergamon 1985.

[35] E.H. Oelkers, F. Poitrasson, Chem. Geol. 191 (2002) 173.

[36] N. Dacheux, N. Clavier, J. Ritt, J. Nucl. Mater. 349 (2006) 291.

[37] A.C. Lasaga, J. Geophys. Res. 89 (1984) 4009.

[38] G.R. Holdren Jr, R.A. Berner, Geochim. Cosmochim. Acta 43 (1979) 1161.

[39] R. Petrovic, Geochim. Cosmochim. Acta 40 (1976) 1509.

[40] W. Stumm, G. Furrer, B. Kunz, Croat. Chem. Acta 56 (1983) 593.

[41] A.C. Thomas, N. Dacheux, V. Brandel, P. Le Coustumer, M. Genet, J. Nucl. Mater. 281 (2000) 91.

[42] A.C. Lasaga, in: "Fundamental Approaches in Describing Mineral Dissolution and Precipitation Rates", A.F. White, S.L. Brantley (Eds.), Rev. Mineral. 31 (1995) 23.

[43] L. Chou, R. Wollast, Am. J. Sci. 285 (1985) 963.

[44] G. Furrer, W. Stumm, Geochim. Cosmochim. Acta 50 (1986) 1847.

[45] H.C. Hegelson, W.M. Murphy, P. Aagaard, Geochim. Cosmochim. Acta 78 (1984) 2405.

[46] A.E. Blum, A.C. Lasaga, Nature 331 (1988) 431

[47] A.C. Lasaga, in: "Kinetics of Geochimical Processes", R.J. Kirkpatrick (Eds.), Rev. Mineral. 8 (1981) 1

[48] N. Clavier, E. du Fou de Kerdaniel, N. Dacheux, P. Le Coustumer, R. Drot, J. Ravaux, E. Simoni, J. Nucl. Mater. 349 (2006) 304.

[49] N. Clavier, in: "Elaboration de Phosphate Diphosphate de Thorium et d'Uranium ( $\beta$-PDTU) et de matériaux composites $\beta$-PDTU/Monazite à partir de précurseurs cristallisés. Etudes du frittage et de la durabilité chimique", PhD Thesis of Université Paris-Sud-11, IPNO-T-04-15, 2004.

[50] N.M. Rose, Geochim. Cosmochim. Acta 55 (1991) 3273.

[51] S.A. Caroll-Webb, J.V. Walther, Am. J. Sci. 290 (1998) 797.

[52] S.T. Tso, J.A. Pask, J. Am. Ceram. Soc 65 (1982) 360.

[53] R.C. Ewing, W.J. Weber, W. Lutze, in: Ceramics : durability and radiation effects, report CONF-951259, 1995.

[54] P. Trocellier, Ann. Chim. Sci. Mat. 26(2) (2001) 113.

[55] K.B. Helean, in: "Zircon dissolution", PhD Thesis of University of New Mexico, 1998. 